\section{Commentary: Time-varying variables - predictively predictive prediction in a coronary artery bypass grafting readmission predictive model}

\author{
Abigail R. Benkert, MD, ${ }^{\mathrm{a}}$ and \\ Shu S. Lin, MD, PhD ${ }^{\mathrm{a}, \mathrm{b}, \mathrm{c}}$
}

Given that readmissions within 30 days following coronary artery bypass grafting (CABG) are common ( 1 in 6 patients), associated with increased complications $(2.8 \%$ in-hospital mortality), and associated with significant costs (\$151 million annual cost to Medicare in 2007), there has been much effort to create and validate readmission predictive models. ${ }^{1,2}$ In this issue of the Journal, Manyam and colleagues $^{3}$ propose a novel model of predicting CABG readmissions that includes using time-varying perioperative data. Previous models have used only time-independent variables, and the authors hypothesized that, by using both time-dependent and time-independent covariates, they can make more accurate predictions. A total of 1303 patients from multiple hospitals within a single health system were included. They combined their institutional Society of Thoracic Surgeons Adult Cardiac Surgery database with their health system's Clinical Data Warehouse and analyzed these 2 data sources. The readmission rate was $7.1 \%$, which is laudably low. After analyzing potential variables, the investigators concluded that inclusion of time-dependent perioperative variables provides a significant improvement to a model that predicts 30-day readmission after CABG.

One could suppose that any such modeling study is a selffulfilling prophecy-the variables that are chosen were

From the a Division of Thoracic and Cardiovascular Surgery, Department of Surgery, Duke University Health System; ${ }^{\mathrm{b}}$ Departments of Immunology and ${ }^{\mathrm{c}}$ Pathology, Duke University School of Medicine, Durham, NC.

Disclosures: The authors reported no conflicts of interest.

The Journal policy requires editors and reviewers to disclose conflicts of interest and to decline handling or reviewing manuscripts for which they may have a conflict of interest. The editors and reviewers of this article have no conflicts of interest.

Received for publication Dec 2, 2020; revisions received Dec 2, 2020; accepted for publication Dec 3, 2020; available ahead of print Dec 17, 2020.

Address for reprints: Shu S. Lin, MD, PhD, Division of Thoracic and Cardiovascular Surgery, Department of Surgery, Duke University Medical Center, Box 3392, Durham, NC 27710 (E-mail: shu.lin@ duke.edu).

J Thorac Cardiovasc Surg 2022;164:956-7

0022-5223/\$36.00

Copyright $₫ 2021$ Published by Elsevier Inc. on behalf of The American Association for Thoracic Surgery

https://doi.org/10.1016/j.jtcvs.2020.12.033

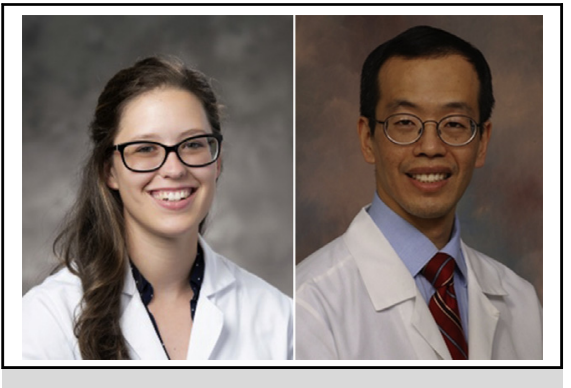

Abigail R. Benkert, MD, and Shu S. Lin, MD, PhD

CENTRAL MESSAGE

The addition of time-dependent perioperative variables to a 30 day $C A B G$ readmission predictive model adds more granular data points and, predictably, improves the accuracy of the model.

picked for good reason. That is, these variables have already passed the initial screening test, based on what is known about CABG. Furthermore, the enthusiasm for the practical value of this type of research may be diminished, since there are usually not unlimited resources available for an institution to start, maintain, and analyze the database(s).

The authors are to be congratulated for a well-written article. While some of the language used to describe the statistical methods are, at times, relatively esoteric, the central message is clear-the novelty of this model is the inclusion of more granular data points of time-varying covariates. Still, the idea that more data would provide a better prediction is predictively logical. Indeed, the strength of this paper is that local clinical data are merged with the Society of Thoracic Surgeons database to provide more granular data points collected during the overall span of a patient's hospitalization.

Of note, the readmission rate is low in this study. While this number may be an underestimation of the true incidence, as some readmissions may not have been captured, it brings up a broader discussion of whether the readmission rate could be affected by the policies set forth by the community. ${ }^{4}$ For example, if we generally did not have a punitive attitude toward a longer postoperative length of stay, then readmission rates may be minimized.

In summary, the authors, using relatively complex statistical methodologies, demonstrated that including time-dependent variables makes the 30-day CABG readmission prediction model much more accurate. While this model is novel, the 
idea that more data give better prediction is predictively logical. Eventually, a practical contribution would be to use the information learned from this study and generate an algorithm that can facilitate discharge decisions to provide high quality follow-up care to minimize readmission following CABG.

\section{References}

1. Rosenblum JM, Lovasik BP, Hunting JC, Binongo J, Halkos ME, Leshnower BG, et al. Predicted Risk of Mortality Score predicts 30-day readmission after coronary artery bypass grafting. Gen Thorac Cardiovasc Surg. 2019;67:661-8.
2. Yale New Haven Health Services Corporation/Center for Outcomes Research and Evaluation. Hospital-level 30-day all-cause unplanned readmission following coronary artery bypass graft surgery: updated measure methodology report. Baltimore, MD: Centers for Medicare and Medicaid Services; 2014.

3. Manyam R, Zhang Y, Carter S, Binongo JN, Rosenblum JM, Keeling WB. Unraveling the impact of time-dependent perioperative variables on 30-day readmission after coronary artery bypass surgery. J Thorac Cardiovasc Surg. 2022;164: 943-55.e7.

4. Warchol SJ, Monestime JP, Mayer RW, Chien WW. Strategies to reduce hospital readmission rates in a non-Medicaid-expansion state. Perspect Health Inf Manag. 2019;16:1a.
See Article page 943.

\section{Commentary: Adding time-dependent variables to readmission predictors - not a perfect solution to limiting readmissions}

\author{
Victor A. Ferraris, MD, PhD
}

Hospital readmissions following cardiac operations surfaced to prominence in 2017, when the US Department of Health and Human Services expanded their financial penalty for hospital reimbursement to include readmissions following coronary artery bypass operations. The unintended consequence of this financial penalty actually might have resulted in higher patient mortality in some "safety net" hospitals caring for indigent and underinsured patients with difficulty in returning to the hospital for postoperative complications. This increased mortality raised concerns about the value of using readmissions as a financial quality measure.

In this issue of the Journal, Manyam and colleagues ${ }^{2}$ present a study that explores the association of time-dependent perioperative variables with 30 -day readmission rate after

\footnotetext{
From the Division of Cardiothoracic Surgery, University of Kentucky and Lexington VA Medical Center, Lexington, Ky.

Disclosures: The author reported no conflicts of interest.

The Journal policy requires editors and reviewers to disclose conflicts of interest and to decline handling or reviewing manuscripts for which they may have a conflict of interest. The editors and reviewers of this article have no conflicts of interest.

Received for publication Nov 4, 2020; revisions received Nov 4, 2020; accepted for publication Nov 4, 2020; available ahead of print Nov 19, 2020.

Address for reprints: Victor A. Ferraris, MD, PhD, Division of Cardiothoracic Surgery, Lexington VA Medical Center, Room B504, 1101 Veterans Drive, Lexington, KY 40502 (E-mail: ferraris@uky.edu).

J Thorac Cardiovasc Surg 2022;164:957-8

0022-5223/\$36.00

Copyright (C) 2020 by The American Association for Thoracic Surgery

https://doi.org/10.1016/j.jtcvs.2020.11.018
}

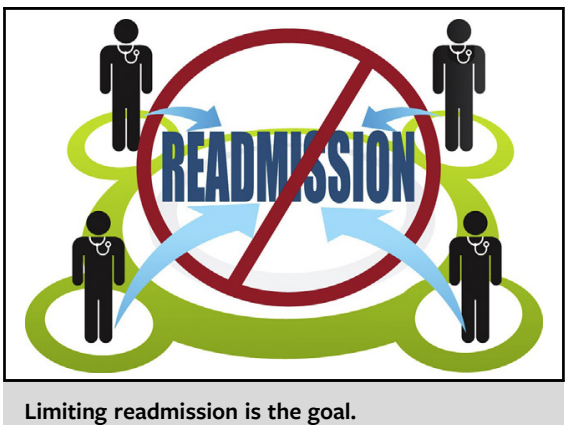

CENTRAL MESSAGE

Adding time-dependent variables

to readmission predictors im-

proves risk prediction but may

provide limited outcome

improvements.

coronary artery bypass operations. They included 6 timedependent variables in their regression model: preoperative hemoglobin A1c level, preoperative creatinine, preoperative hematocrit, intraoperative hemoglobin, postoperative creatinine, and postoperative hemoglobin. The adequacy of the final prediction model was excellent, with an area under the curve value of $\sim 0.9$. They concluded that the addition of time-dependent perioperative variables into risk prediction models provides better prediction and more accurate models for predicting readmission.

Technically, the authors used a static model, which converts time-dependent variables into variables with several discrete values at 2 or more times of interest, such as before and after an operation. This is much different, and much simpler from a computational standpoint, than including time-dependent variables as a continuous variable with a 